\title{
Chapter 15 \\ Integrating Ecology and Evolutionary \\ Theory: A Game Changer for Biodiversity \\ Conservation?
}

\author{
Silvia Di Marco
}

\begin{abstract}
Currently, one of the central arguments in favour of biodiversity conservation is that it is essential for the maintenance of ecosystem services, that is, the benefits that people receive from ecosystems. However, the relationship between ecosystem services and biodiversity is contested and needs clarification. The goal of this chapter is to spell out the interaction and reciprocal influences between conservation science, evolutionary biology, and ecology, in order to understand whether a stronger integration of evolutionary and ecological studies might help clarify the interaction between biodiversity and ecosystem functioning as well as influence biodiversity conservation practices. To this end, the eco-evolutionary feedback theory proposed by David Post and Eric Palkovacs is analysed, arguing that it helps operationalise niche construction theory and develop a more sophisticated understanding of the relationship between ecosystem functioning and biodiversity. Finally, it is proposed that by deepening the integration of ecological and evolutionary factors in our understanding of ecosystem functioning, the eco-evolutionary feedback theory is supportive of an "evolutionary-enlightened management" of biodiversity within the ecosystem services approach.
\end{abstract}

Keywords Ecosystem functions $\cdot$ Evolution $\cdot$ Niche construction $\cdot$ Ecosystem engineering $\cdot$ Conservation biology

\subsection{Introduction}

Currently, one of the central arguments in favour of biodiversity conservation is that it is essential for the maintenance of ecosystem services, that is, the benefits that people receive from ecosystems (MA 2003, 2005). However, as remarked by Georgina Mace and colleagues, although both biodiversity and ecosystem scientists implicitly acknowledge that biodiversity plays different roles at the different levels

\footnotetext{
S. Di Marco $(\varangle)$

Centro de Filosofia das Ciências da Universidade de Lisboa, Lisbon, Portugal

e-mail: sdmarco@fc.ul.pt
}

E. Casetta et al. (eds.), From Assessing to Conserving Biodiversity, 
of the ecosystem services hierarchy, their approach to biodiversity conservation remains fundamentally different. Conservation biologists typically struggle to develop an evidence base that supports the protection of biodiversity, in particular charismatic and endangered species, as a good endowed with cultural, scientific and even "intrinsic" value, while ecologists focus on the contribution provided by biodiversity, usually understood as functional diversity, to ecosystem processes and services (Mace et al. 2012). Face to the challenges posed by the ecosystem services approach to biodiversity conservation, this mismatch amongst professionals is a reason of concern. Still, the growing interest amongst ecologists for the feedbacks between organisms and ecosystems promises to shed new light on the interactions between biodiversity, ecosystem processes and ecosystem services, and has the potential to influence biodiversity conservation planning.

In this regard, various authors stress the fact that since the introduction of the concept of ecosystem service in conservation policies, community and ecosystem ecologists have paid more and more attention to biodiversity, especially species and genes diversity, as a driver of ecosystem functioning (Naeem 2002; Loreau 2010). In particular, Michel Loreau has argued that if ecologists are to understand and model the effects of biodiversity on the functioning of ecosystems, they have to develop new theories to connect the dots that link the evolution of species traits at the individual level (evolutionary biology), the dynamics of species interactions (community ecology) and the overall functioning of ecosystems (ecosystem ecology) (Loreau 2010). An endeavor whose difficulties cannot be understated, especially if one takes into account the "explanatory reversibility" of the concept of biodiversity in ecology, ${ }^{1}$ and the philosophical issues posed by both the notion of ecosystem function and the idea that organisms play a role in an ecosystem. ${ }^{2}$

Bracketing these questions, as well as the problems posed by the polysemy of 'biodiversity', ${ }^{3}$ the present chapter aims to spell out the interaction and reciprocal influence between conservation science, evolutionary biology, and ecology, in order to understand whether a stronger integration of evolutionary and ecological studies might help clarify the relationship between biodiversity and ecosystem functioning, and influence biodiversity conservation practices within the ecosystem services approach.

To this aim I will first describe the divide between what Mace et al. (2012) have called the "ecosystem services perspective" and the "conservation perspective" within the ecosystem services approach, and present Loreau's view on the possible integration of ecological and evolutionary studies. Subsequently, I will analyse the eco-evolutionary feedback theory by Post and Palkovacs (2009), as an example of such integration. In particular, I will argue that this theory helps operationalise the evolutionary concept of niche construction (Laland et al. 1999; Odling-Smee et al. 2003), and offers theoretical instruments to develop a more sophisticated understanding of the relationship between ecosystem functioning and biodiversity.

\footnotetext{
${ }^{1}$ See Huneman, Chap. 13, in this volume.

${ }^{2}$ See Dussault, Chap. 14, in this volume.

${ }^{3}$ See Toepfer, Chap. 16, and Meinard et al., Chap. 17, in this volume.
} 
Finally, ${ }^{4}$ I will argue that by deepening the integration of ecological and evolutionary factors in our understanding of ecosystem functioning, the eco-evolutionary feedback theory is supportive of an "evolutionary-enlightened management" (Ashley et al. 2003) of biodiversity within the ecosystem services approach.

\subsection{On the Relationship Between Biodiversity and Ecosystem Services}

Ecosystem services are the benefits that humans derive, directly or indirectly, from the ecosystems or, phrased differently, they are "the functions and processes of ecosystems that benefit humans" (Costanza et al. 2017). They are classified into provisioning services, such as food, clear water, timber, and fuel; regulating services, such as flood protection, pests control, and climate regulation; supporting services, corresponding to basic ecosystem processes such as primary production, soil formation, and nutrients cycle; and cultural services, corresponding to a range of cultural benefits - e.g., aesthetic, recreational, or spiritual - that people receive from ecosystems.

\subsubsection{Ecosystem Services in Brief}

The idea of ecosystem service is a socio-economic concept that dates back to 1977, when Science published the article "How much are Nature's services worth?" by Walter Westman, but gained momentum in the academia only in 1997, with the publication of the book Nature's Services: Societal Dependence on Natural Ecosystems (Daily 1997) and an article by Robert Costanza and colleagues on the value of the world's ecosystem services and natural capital (Costanza et al. 1997). The goal of these publications was to make explicit the contribution of ecosystems to human well-being, and put an economic value on it (between 16 and 54 trillion USD per year at the time), in order to make transparent the trade-offs involved in any decision concerning the use of land and natural resources. This monetary approach stirred a fierce debate, which is still ongoing, but eventually the concept of ecosystem service met biodiversity conservation: first, in 2001, with the launch of the Millennium Ecosystem Assessment (MA) by the United Nations Environment Programme, and later, in 2007, with The Economics of Ecosystems and Biodiversity (TEEB) initiative promoted by the German Government and the European Commission. These programmes are focused, respectively, on the ecological and economic aspects of ecosystem services, and are based on a utilitarian view of biodiversity (biodiversity must be preserved as an ecosystem service in itself, or as a

\footnotetext{
${ }^{4}$ With an argument intersecting that expounded by Alessandro Minelli, Chap. 11, in this volume.
} 
component of the environment necessary for the maintenance of other ecosystem services), and on the implicit (and controversial) assumption that the protection of the ecosystem services leads to the protection of biodiversity (Mace et al. 2012).

\subsubsection{Ecosystem Services and Biodiversity: Epistemological and Ethical Troubles}

Biodiversity is considered a cultural service or an actual good (which might be marketable or not) when it provides non-material benefits to human beings. Wildlife, uncontaminated landscapes, totemic, charismatic and rare or endangered species have a particular appeal to human beings, because they respond to aesthetic, spiritual, religious, educational and recreational values. In these cases, people value the diversity of life as such - or some specific actualization of that diversity, as for instance charismatic species - and not some product or purported effect of biodiversity (e.g., variety of food or possibility to discover new drugs). ${ }^{5}$ For all the other services, the relationship between biodiversity and human benefits is all but clear and needs to be examined on a case by case basis (Harrison et al. 2014). As a general rule, there is stronger evidence for the effects of biodiversity on ecosystems stability than on ecosystem services (Cardinale et al. 2012; Srivastava and Vellend 2005), and although it is generally agreed that biodiversity plays an insurance role, by potentially buffering ecosystems against environmental changes (Cottingham et al. 2001; Hooper et al. 2005; Loreau 2010a), data reviews and meta-analysis on the threefold relationship between biodiversity, ecosystem functioning, and ecosystem services are hampered by the lack of unified definitions and measures of biodiversity, and by the complexity and multi-faceted nature of each of the factors of the equation (Cardinale et al. 2012; Mace et al. 2012). Also, in many cases it is difficult to establish if the biodiversity effect is due to diversity as such (e.g., at the level of species, genes, or traits) or to other factors such as composition or biomass.

As mentioned above, within the ecosystem services approach, ecosystem services and biodiversity are often used as synonyms, thus implying that they are the same thing and that, by protecting one, we are automatically protecting the other (Costanza et al. 2017; TEEB 2010). On the contrary, within the conservationist perspective, biodiversity is an ecosystem service or a good per se, and as such it does not necessarily contribute to other ecosystem services and is potentially in conflict with them. Both positions have pitfalls. For what concerns the conservationist perspective, the main problem is that it is blind to the functional role of biodiversity, and often focuses on charismatic or endangered species. In so doing it loses sight of the greater variety of units, levels and scales at which biodiversity occurs, and perpetuates a static vision of life both at the species and ecosystem level. On the contrary, within the ecosystem services perspective, the functional role of biodiversity

\footnotetext{
${ }^{5}$ But for a problematisation of the relationship between biodiversity and cultural services see, for instance, Sarkar 2005, Cardinale et al. 2012.
} 
is acknowledged, but in practice ecologists account for its contribution to the ecosystem almost exclusively in terms of simple trophic structures and the related stocks and flows of energy, nutrients and biomass. This poses epistemological problems related to the different aims, conceptual frameworks, and methodologies adopted in different scientific disciplines, where such problems call for theoretical and empirical solutions. Also, values of biodiversity other than its contribution to ecosystem functioning are not taken into account, thus posing an ethical problem (Mace et al. 2012).

The ethical criticism is the one most often leveraged against the ecosystem services approach (Reyers et al. 2012), and can be framed within a number of related debates: the controversy on the monetary nature of the concept of ecosystem service (e.g., McCauley 2006; Redford and Adams 2009); the debate about the instrumental versus intrinsic value of biodiversity (e.g., Norton 1986; Sarkar 2005; Maquire and Justus 2008; Justus et al. 2009); or the opposition between ecocentrism and anthropocentrism in environmental ethics (e.g., Singer 1975; Thompson and Barton 1994; Naess 1973). In this chapter, I let aside the ethical issues and focus on the epistemological problems instead, trying to understand whether a stronger integration between ecology and evolutionary theory might make a difference in conservation planning within the ecosystem services approach.

\subsubsection{Ecosystem Services and Biodiversity: An Ecologist's Perspective}

For those who embrace the conservation perspective, there is a potential opposition between biodiversity and ecosystem services, and some authors see the ecosystem services approach as an unwarranted thwarting of the original mission of conservation, namely, the protection of biodiversity or, more generally, nature, for its own sake (e.g., McCauley 2006; Redford and Adams 2009). From this perspective, the ecosystem services approach is detrimental to biodiversity conservation. However, if one tackles this criticism from an epistemological point of view, letting aside the controversy concerning the value of biodiversity, it becomes apparent that the endorsement of the concept of ecological service in many conservation policies has produced at least one major benefit for biodiversity science in that it has given special impulse to the study of the effects of biodiversity on ecosystem functioning in experimental and theoretical ecology (Loreau 2010). According to Loreau, this had relevant consequences for ecology both at the epistemological and disciplinary level. At the epistemological level, it has revived and reshaped the diversity-stability debate - that has run through ecosystem ecology since the 1950s (e.g., MacArthur 1955; May 1973; Pimm 1984) —, and has given momentum to the study of the respective roles of individual-level and ecosystem-level selection in shaping ecosys-

\footnotetext{
${ }^{6}$ See Huneman, Chap. 13, in this volume, for a discussion of the notions of diversity used in the formulation and test of the stability hypothesis (biodiversity as an explanans).
} 
tem properties - a controversial issue in both ecology and evolutionary biology (see Williams and Lenton 2007; Loreau 2010b). More importantly, it has changed the way ecosystem and community ecologists approach the study of biodiversity, giving prominence to the idea that biodiversity, especially species and genes diversity, is a driver of ecosystem functioning (Naeem 2002; Loreau 2010), and populations cannot be studied as homogeneous biomass pools in which individuals operate in identical ways to influence the nutrient and energy flows amongst the ecosystem compartments (Bassar et al. 2010).

At the disciplinary level, the need to better understand the effects of biodiversity on ecosystem functions at different spatial and temporal scales has made more evident and urgent the importance of integrating community ecology, ecosystem ecology and evolutionary biology (Loreau 2010, b). ${ }^{7}$ Indeed, the development of the ecosystem services approach in environmental protection and biodiversity conservation has not only turned the study of the relationship between biodiversity and ecosystems into a pressing scientific matter, imposing a research agenda on ecologists (i.e., to understand the role and relevance of biodiversity for the delivery of ecosystem services). It has also implicitly indicated the scientific hypothesis to be tested, namely that biodiversity is necessary for ecosystem processes and that the loss of biodiversity hampers the functioning of ecosystems in the short and/or long term, thus affecting the provision of ecosystem services.

To answer the practical questions raised by the ecosystem services approach it is necessary to understand how ecosystems function and predict how they might change under a variety of environmental and anthropic pressures, such as climate change, habitat loss and degradation, overharvesting and diffusion of invasive exotic species. All these factors affect biodiversity as much as ecosystems as a whole. Loreau agrees with Mace and colleagues that current models of interaction between biodiversity and ecosystem functioning, based mostly on the modelling of evolutionary complex food webs, have several limitations. He stresses that important insights might come from theories such as ecosystem engineering (Jones et al. 1994, 1997; Wright and Jones 2006) and niche construction (Laland et al. 1999; OdlingSmee et al. 2003), which try to account for the ability of organisms to transform their habitat with relevant consequences both at the ecological and evolutionary level. In the last decade, there has been a surge of interest for eco-evolutionary theories (Whitham et al. 2006; Fussman et al. 2007), particularly in theoretical ecology (Kokko and Lopez-Sepulcre 2007). In what follows I present and discuss David Post and Eric Palkovacs' eco-evolutionary feedback (EEFB) theory, because it is an interesting example of ecological re-elaboration and clarification of the niche construction theory (henceforth NCT) originally formulated by Kevin Laland and John Odling-Smee, and also because Post and Palkovacs suggest that an integration of ecological and evolutionary theories would have relevant consequences not only for our understanding of ecosystem functioning, but also for biodiversity conservation.

\footnotetext{
${ }^{7}$ But see Huneman, Chap. 13, in this volume, for a criticism of this endeavour.
} 


\subsection{Eco-Evolutionary Feedback Theory}

An eco-evolutionary feedback is "the cyclical interaction between ecology and evolution such that changes in ecological interactions drive evolutionary change in organismal traits that, in turn, alter the form of ecological interactions, and so forth" (Post and Palkovacs 2009). This description of the reciprocal causation between ecological and evolutionary change clarifies the ecological relevance of NCT by making a clear distinction between the process of niche construction, defined as "the effect of an organism on its environment" (Post and Palkovacs 2009), and the evolutionary feedbacks that occur in response to the environmental changes caused by organisms. Niche construction sensu stricto (Post and Palkovacs 2009) includes both active engineering and the effects caused by the by-products of biological process, while the evolutionary feedback can be the result of heritable traits change or phenotypic plasticity. By explicitly separating the general process of EEFB into two sub-processes (niche construction + evolutionary feedback), EEFB theory makes clear that not all the biotic processes that shape the environment can cause subsequent evolution, because many factors can prevent the evolutionary feedback. However, when the feedback occurs, it has important consequences at both the evolutionary and ecological level, because it can affect the direction of evolution and alter the role of species in the ecosystem. It also highlights that both processes, even when they do not occur together, have important ecological and evolutionary consequences, hence deserving in-depth study. Finally, unlike NCT, at least in its initial version, EEFB allows for cases in which the recipient population of the modified selective pressure can be different from the population that produced the environmental transformation in the first place (see Odling-Smee et al. 2013; Barker and Odling-Smee 2014).

For an EEFB to occur, three conditions need be satisfied: (1) organisms must have a phenotype that strongly impacts the environment, i.e., they must structure or construct their niche (e.g., nutrients cycling and translocation, habitat construction and modification, consumption $)^{8} ;(2)$ the changes produced in the environment must cause selection on a population and that this population has sufficient genetic capacity to evolve in response to changes in the environment; (3) the time-scales of the ecological and evolutionary responses have to be congruent, i.e., the constructed niche must persist for a duration that is sufficient to select the relevant traits (this corresponds to the concept of ecological inheritance in NCT).

For what concerns (2) it should be noticed that, as in adaptive evolution more generally, the evolutionary factors that determine whether a population will evolve or go extinct are a combination of genetic factors (e.g., high levels of genetic variation are expected to favour evolutionary change); demographic factors (e.g.,

\footnotetext{
${ }^{8}$ Potentially, all organisms are niche constructors, because all organisms interact with the environment. However, as it will be explained below, a key factor for the identification of meaningful cases of niche construction in the EEFB theory is the strength (magnitude and/or extent) of the interaction between an organism and the environment (which includes other organisms), and the spatial and temporal scale of the effects of such interaction.
} 
population size and genetic drift); and ecological factors (e.g., the rate of deforestation or the introduction of a toxic compound).

For what concerns (3), what counts as a sufficient duration will depend on the niche, as well as on the species and traits under consideration. In any case, there must be an overlap of ecological and evolutionary time: the constructed niche must persist long enough to produce evolutionary effects, and evolution must be fast enough to feed back on the constructed niche and further influence it. Since what matters is the congruence between ecological and evolutionary time, in principle evolution does not need to be rapid for EEFB to emerge. Slow niche construction, such as the oxygenation of earth's atmosphere by cyanobacteria, can create ecoevolutionary feedbacks as much as rapid evolution associated with rapid niche construction. However, the study of EEFB associated with rapid evolution has the advantage of being more easily amenable to empirical tests, and is more likely to be relevant in terms of biodiversity protection and ecosystem services conservation practices.

\subsubsection{EEFB and Contemporary Evolution: Three Empirical Cases}

The existence of rapid contemporary evolution, i.e., the evolution of heritable traits over a few generations (Stockwell et al. 2003; Jones et al. 2009), ${ }^{9}$ is neither particularly controversial in ecology nor in evolutionary biology. What is controversial is the overall ecological and evolutionary relevance (prevalence and magnitude) of this phenomenon. As a matter of fact, in spite of the accumulation of studies that in the course of the last 40 years have shown that a strict distinction between ecological and evolutionary time is unwarranted, ecologists still tend to ignore potential effects of evolution on ecological interactions, because they assume that evolution occurs on a much slower time scale than ecological dynamics (Bassar et al. 2010). On the other hand, evolutionary biologists tend to ignore the action of organisms on their environment, because it is considered too weak and flimsy to significantly change selection pressures (Laland and Sterelny 2006). Eco-evolutionary theories challenge these entrenched views. In fact, there is growing evidence that contemporary evolution is a widespread phenomenon-which concerns many traits and many organisms from all kingdoms - and the evidence for potential cases of ecoevolutionary feedbacks is growing. Here I summarise three of the five empirical cases reviewed by Post and Palkovacs (2009): alewives' speciation caused by patterns of migration, its influence on zooplankton communities, and the subsequent evolution of foraging traits; the effect of the life histories of Trinidad guppies on

\footnotetext{
${ }^{9}$ Rapid evolution, contemporary evolution and microevolution are sometimes used as synonyms, and definitions vary (e.g., Thompson 1998, Kinnison and Hairston 2007, Ashley et al. 2003). Here I follow Post and Palkovacs 2009 and use contemporary evolution to refer to the overlap of ecological and evolutionary times, irrespectively of the actual duration of the process.
} 
nutrient cycling and its potential feedback on male guppies' phenotype; the soilmediated impact of Populus leaf tannins levels on the development of adapted roots.

\subsubsection{Alewives and Zooplankton}

Along North America East coast, the ecological isolation of lakes from the ocean has led to the phenotypic differentiation of alewife (Alosa pseudoharengus) landlocked populations that differ from the original anadromous population in feeding morphology and prey selectivity. Anadromous fishes migrate up rivers from the ocean to spawn and then go back to the open sea. In this case, the alewives only temporarily affect the community structure of lacustrine zooplankton (niche construction via predation, Post and Palkovacs 2009) before they go back to the ocean, thus the duration of the constructed niche is not long enough to cause an ecoevolutionary feedback. On the contrary, in the landlocked populations, intense yearround predation pressure eliminates large-bodied preys and produces a lacustrine zooplankton community of relatively low biomass of small-bodied zooplankton throughout the year (persistent constructed niche). This exerts a strong selection for traits related to foraging on small zooplankton, so that the landlocked population has developed smaller mouth gape and narrower spacing between gill rakes compared to the ancestral anadromous population (evolutionary feedback). In this case there is strong evidence for a complete EEFB.

\subsubsection{Trinidad Guppies and Nutrients Cycling}

Observations in the wild have shown that the life-histories (age and size at maturity) of Trinidad guppies (Poecilia reticulata) are affected by predation pressure. In highpredation environments, guppies reach maturity at an earlier age and smaller size, and they reproduce more frequently giving birth to smaller offsprings, with important effects for the population phenotype. Mesocosm experiments have shown that under conditions of equal biomass, populations characterised by a high number of small individuals (high-predation environment) drive higher nutrients flows compared to populations with fewer larger individuals (low-predation environment), thus increasing the rates of primary production, i.e., algal biomass (constructed niche). This, in turn, might influence further differentiation amongst guppies' populations, for instance, by influencing traits such as male colour patterns, which are under natural and sexual selection, and are sensitive to the levels of algae-derived carotenoids in the environment (potential eco-evolutionary feedback). 


\subsubsection{Populus and Soil Nutrients Levels}

Poplar trees are foundation species whose chemical effects on leaf litter strongly influence community dynamics and ecosystem processes. Observational studies have shown that intraspecific variation in condensed tannin levels in poplar trees' leaves controls decomposition and nitrogen mineralisation rates, as well as the composition of the microbial community in the soil, thus creating a microhabitat (constructed niche). Since high concentrations of tannins inhibit nutrients release from leaves litter, poplar trees with high tannin levels will have to cope with low nutrients levels. According to EEFB theory, these trees should display some form of adaptation. Indeed, a strong positive correlation between leaf tannin levels and the development of finer roots has been observed, thus providing indirect evidence for eco-evolutionary feedback. However, ecological factors such as the presence of other plant species, herbivores and nutrients loading might disrupt or reduce the strength of the feedback by altering the ecology of the soil.

It is worth noticing that it is not always clear whether contemporary evolution is due to heritable traits or phenotypic plasticity. However, as remarked by Palkovacs et al. (2012), although such distinction is fundamental to our understanding of evolutionary and ecological processes, in the context of conservation biology it might be more important, and urgent, to link phenotypic change and ecosystem dynamics, regardless of the specific causes of change. Also, considering that plasticity itself is a hereditary trait that evolves and can direct future phenotypic change, it is not always useful to draw a thick line between plasticity and genetic change in terms of potential ecological causes and effects (Ghalambor et al. 2007; Palkovacs et al. 2012). ${ }^{10}$ What is most relevant here is to highlight that the species more likely involved in EEFB are also the most relevant in terms of ecosystem functioning, because they strongly affect the community and the ecosystem where they live. They can be keystone, foundation, or dominant species, ecosystem engineers, or species that alter nutrient cycles through translocation or recycling.

\subsubsection{EEFB, Niche Construction, and Ecosystem Engineering}

What all these organisms have in common is that they are strong interactors. ${ }^{11}$ To be a strong interactor, however, often depends on the ecological context: foundation species in one habitat might be rare in another, weak interactors in species-rich communities might have strong effects in species-poor communities, and species that move nutrients will have very different impacts in low- compared to highnutrient environments (Post and Palcovaks 2009; Paine 1966; Menge et al. 1994).

\footnotetext{
${ }^{10}$ See also Minelli, Chap. 11, in this volume.

${ }^{11}$ For a detailed discussion of the differences between strong interactors, in particular between keystone species and ecosystem engineers see Boogert et al. 2006.
} 
Thus, the ability of a species to construct a persistent niche often depends on the overall conditions of the ecosystem and the community, which means that it can vary in space and time. In turn, the eco-evolutionary feedback, with its potential to alter and respond to environmental selective pressure, can lead to the differentiation of a population whose ecological role is different from that of the original population, thus affecting community and ecosystem dynamics. Indeed, there might be instances in which the change of the traits of a species is at least as important as its presence/absence in terms of ecological effects. In the case of the alewives from North American coastal lakes, for example, there is evidence that the differentiation of the landlocked population has influenced the evolution of one of its preys, Daphnia ambigua, and this is likely to cause further effects on trophic cascades, because Daphnia is itself a strong interactor (a dominant grazer for zooplankton) (Palkovacs et al. 2012).

A main feature of EEFB theory is that it highlights the fact that organisms actively build their environment and that species, species traits, and species ecological impacts are dynamic and vary across space and time. A consequence of this is that within the research framework set by eco-evolutionary theories, the functional role of biodiversity in an ecosystem cannot be understood simply in terms of more or less complex trophic webs. This simplifying idealisation has been at the core of the success of ecosystem ecology in the study of terrestrial global biogeochemistry, but it has been increasingly called into question by ecologists themselves at least since the 1990s (Loreau 2010). In particular, the concept of ecosystem engineering introduced by Clive Jones and colleagues (Jones et al. 1994, 1997; Wright and Jones 2006), often considered the ecological counterpart of Laland and Odling-Smee's NCT, has shown that connectance webs that describe the processes driven by ecosystem engineers should be studied along with trophic webs, if we are to accurately model the interactions between communities and ecosystems. Importantly, these studies have shown that the laws of conservation of mass and energy, as well as the stoichiometry rules used to model trophic webs, cannot be used to predict the structure and outputs of ecosystem engineering networks, for which specific qualitative and quantitative models have been proposed (Jones et al. 1997; Boogert et al. 2006).

Ecosystem engineers are "organisms that directly or indirectly modulate the availability of resources (other than themselves) to other species, by causing physical state changes in biotic and abiotic materials. In so doing they modify, maintain and/ or create habitats" (Jones et al. 1994). Within EEFB theory, they are seen as strong candidates for eco-evolutionary feedbacks, together with keystone species (species, usually predators, whose impact on their community or ecosystem is much larger than would be expected from their abundance), dominant species (species that outnumber their competitors in abundance or total biomass), and foundation species (species that strongly influence the structure of the community, e.g., by creating habitats). Accordingly, studying ecosystems from an EEFB theory perspective implies to parse strong ecological interactors according to a range of qualitative and quantitative models, e.g., strong per capita interactions that produce effects in the short term $v s$. weak but continuous per capita interactions that produce cumulative effects in the long term. Trophic webs, then, are but one of the interaction networks that compose 
the overall connectivity of the ecosystem. The other crucial ecological relationships that need attention are the non-trophic interaction webs described by ecosystem engineering theory, and the environmentally-mediated gene-associations (EMGAs) theorised by Odling-Smee and colleagues (Odling-Smee et al. 2003, 2013; Barker and Odling-Smee 2014), in a development of the original NCT, prompted by the insights provided by ecosystem engineering and eco-evolutionary theories.

\subsubsection{EEFB and Environmentally-Mediated Gene-Associations}

EMGAs are "indirect but specific connections between distinct genotypes mediated either by biotic or abiotic environmental components in the external environment [...]. They map sources of selection stemming from one population's genes onto genotypes in another population that evolve in response to those modified sources" (Odling-Smee et al. 2013). These indirect evolutionary interactions mediated by the environment emerge when the niche constructed by a population-via its physiological processes as well as active engineering-influences the selective pressure acting on the same population or, more often, on a different population of different species. For example, in the case of Trinidad guppies, predators, through differential predation pressure, can influence guppy populations' life histories, leading to the differentiations of populations of larger or smaller guppies, characterised by different rates of excretion that determine differential inorganic nutrients distribution. This, in turn, affects algal growth, which has the potential to feed back on the selection of male guppy colour patterns through the concentration of carotenoids released by algae in the environment.

The idea of EMGAs helps formalise the causal chain of EEFB in genetic terms, and can be used to visualise the ramifications of evolutionary and ecological effects deriving from niche construction via biotic or abiotic mediations. In its original form, it gives epistemic priority to the genetic component within the EEFB's causal chain, but in those cases in which the niche construction is underpinned by nonheritable variation, environmentally-mediated genotypic-associations are replaced by environmentally-mediated phenotypic-associations (EMPAs), thus emphasising that the phenotype should not be thought of as the mere epiphenomenon of genetic information, but as the dynamic result of the combination of heritable variation with a number of non-heritable factors, such as plasticity, epigenetics and population structure (Odling-Smee et al. 2013).

It follows that, in order to respond to the requirements of EEFB theory, the study of ecosystem processes and functioning should be articulated along two interrelated axes, which force ecosystem ecology to revise its operational simplifying idealisations. On the one hand, the study of the sub-process of niche construction requires the development of ecosystem models that account for high degrees of connectance at the different scales of the ecosystem, integrating trophic and competitive webs with more complex interaction webs, as well as EMGAs or EMPAs; on the 
other hand, the study of the sub-process of evolutionary feedbacks needs to be carried out taking into account both genetic and non-heritable phenotypic variation, because both can be sources of functional evolution and adaptation. Accordingly, functional diversity must be understood as a dynamic epiphenomenon that can potentially emerge from both genetic and non-genetic factors that need to be studied on a case by case basis.

All in all, what emerges from EEFB theory is a highly dynamic picture of ecosystems, populations and communities, in which the structure of biodiversity-used here as a shorthand for diversity at the level of species, genes, traits, communities, etc. - can vary more easily than both ecologists and evolutionary biologists are prone to believe, and where the causal chain of change does not go exclusively from the environment to the organism (ecological change as a cause of trait change), but can go from the organism to the environment (trait change as a cause of ecological change). In the next section, I explore the potential consequences of this shift of perspective for conservation biology.

\subsection{Eco-Evolutionary Feedback Theory: Some Consequences for Biodiversity Conservation}

The study of EEFB pushes ecologists to recognise that contemporary evolution creates phenotypic differences that can alter the role of a species in a community or ecosystem at ecological time-scales. This implies that evolution can no longer be considered mere background noise in the study of ecosystem dynamics, and extant and potential novel biodiversity become a fundamental component of the study of ecosystem dynamics. For Post and Palkovacs: "the study of eco-evolutionary feedbacks focuses attention on the bidirectional interactions that unify ecology and evolution, and highlights the importance of conserving both ecological and evolutionary diversity in nature" (Post and Palkovacs 2009). But how, exactly, could EEFB theory guide biodiversity conservation? As referred to in Sect. 15.1, a criticism leveraged by conservation biologists to ecologists within the ecosystem services approach is that they account for biodiversity's contribution to ecosystem functions almost exclusively in terms of simple trophic structures (Mace et al. 2012). What kind of instruments does EEFB theory offer to tackle this issue?

\subsubsection{Ecosystem Engineers First?}

Considering that EEFB theory has many points in common with the ecosystem engineering theory, some important insights about the impact of eco-evolutionary theories on biodiversity conservation can be found in Crain and Bertness 2006 and in Boogert et al. 2006. For these authors, ecosystem engineers should be the primary targets of biodiversity conservation policies, because they shape habitats and 
ecosystems, with all their related species and functions. Since ecosystem engineers are responsible for a much higher and more complex level of inter-species connectance than the trophic webs generated by other organisms, the loss of ecosystem engineers is more likely to have far reaching negative consequences on both communities and whole ecosystems (Crain and Bertness 2006. See also Jones et al. 1997; Wright and Jones 2006). Although species that are ecosystem engineers under certain circumstances may not be so under others, it is possible to identify fundamental engineering roles in ecosystems, independently of the specific species involved. Accordingly, to grant stability to ecosystem structure and functioning, conservation policies should focus on protecting the activity of key engineers, rather than the species composition of an ecosystem (Boogert et al. 2006; see also OdlingSmee et al. 2003). This is a classical argument in favour of the preservation of functional diversity rather than species diversity, and is usually criticised for being too narrow a criterion for selecting the aspects of biodiversity worth protection (Mace et al. 2012). To preserve ecosystem functioning, in fact, we do not need to protect all the species that perform a given function and their genetic variability. For instance, we do not need to protect all the species of trees in a forest, and their intraspecific variation, to ensure biomass production, oxygen emission, and $\mathrm{CO}_{2}$ sequestration. From this perspective, the most efficient course of action would be to select the species that better perform the function of interest, and focus our conservation efforts on them. This approach is likely to leave aside rare species, which represent a primary target for conservation biology, because their functional role on an ecosystem is often negligible. In this respect, not only do aspects of biodiversity not related to ecological functions become irrelevant, but the replacement of ecosystem engineering species using artificial solutions becomes an acceptable option (e.g., replacing of caterpillars by artificially created leaf ties, see Lill and Marquis 2003). Here, at least in principle, the choice to favour technological solutions over biodiversity conservation will be constrained by considerations of efficacy and costeffectiveness (Boogert et al. 2006), rather than by an a priori obligation to avoid species extinction, or a precautionary approach whereby a species (or a genome) that has no particular functional import under the present conditions might become relevant under different conditions, because of ecological changes or because our knowledge of the benefits we obtain from that particular species/genome changes (see Maclaurin and Sterelny 2008; Sarkar 2005). Thus, although there are compelling reasons for choosing ecosystem engineers as targets of biodiversity conservation, this choice must be further qualified and refined.

\subsubsection{Genetic Diversity: Better Safe than Sorry}

Niche construction (of which ecosystem engineering is just one possible case) is only one half of the EEFB process. The other is evolutionary feedback. To the extent that evolutionary feedbacks have the potential to produce relevant ecological effects, they should be taken into account in conservation policies aimed at preserving ecosystem functions. Since one of the conditions for EEFB is that the population(s) 
affected by the constructed niche must have sufficient genetic capacity to evolve in response to new selective pressures before going extinct, it follows that it is important to preserve not only functional diversity, but also genetic diversity (that might include phenotypic plasticity), because this ensures that niche constructing species, or other species potentially affected by the constructed niche, will maintain their ability to respond to environmental modifications. In this respect, it should be noted that trait change per se is not a guarantee of ecosystem stability, because phenotypic variation can be both a driver of or a buffer against ecological change. In the empirical cases described in Sect. 15.3.1, in fact, the putative evolutionary feedback works clearly as a stabiliser of functions only in the case of poplar trees, while in the cases of the alewives and Trinidad guppies the evolutionary feedback potentially causes a cascade of changes in the community structures whose consequences in terms of ecosystem functions need further clarification. This only makes the need to improve our understanding of eco-evolutionary interactions more compelling, in order to be able to predict when they could buffer the ecosystem and when they would magnify potential functional disruptions. Sweeping generalisations are not warranted in this relatively recent domain of inquiry, but there is evidence that contemporary evolution is most common, although less evident, when it counteracts phenotypic changes caused by environmental pressure, thus buffering ecosystem functions (Ellner et al. 2011; Palkovacs et al. 2012). Preserving the genetic diversity that feeds contemporary evolution, then, seems a safe bet.

Without entering into the debate on what genetic diversity exactly is, how to measure it, and what to do to preserve it (see Mace and Purvis 2008 for a list of problems in this field), we can say that, by providing a clear and well-structured theoretical framework for the empirical study of the reciprocal interaction between evolutionary and ecological processes, EEFB theory offers decisive evidence for the necessity of keeping into account evolutionary dynamics in the study of ecosystem functioning. Accordingly, it provides arguments to support the importance of "evolutionaryenlightened management" in biodiversity conservation (Ashley et al. 2003). In fact, whether the eco-evolutionary feedbacks magnify ecological change or buffer against it, they must be taken into account if we are to preserve ecosystems functioning.

\subsubsection{EEFB Theory and Evolutionary-Enlightened Management}

For the proponents of evolutionary approaches to biodiversity protection, conservation policies are hampered by the misplaced idea that while human disturbance is very fast, adaptation is a very slow process, thus irrelevant to conservation planning, whose temporal horizon seldom exceeds a few decades (Mace and Purvis 2008). Typological thinking concerning both species and ecosystems is another hindrance to evolutionary-enlightened management, since it promotes the idea that evolutionary change has relevant consequences at an ecological and human time-scale only when it concerns organisms with short generation time (e.g., microorganisms). 
Consequently, it is argued, its effects on the whole of biodiversity are negligible (Ashley et al. 2003; Santamaria and Mendez 2012). Mary Ashley and colleagues also remark that, although in conservation planning it is theoretically acknowledged that species respond to change both ecologically and evolutionarily, in practice the importance of evolutionary responses is often neglected. For instance, research models on potential impacts of rising temperature and $\mathrm{CO}_{2}$ concentrations generally make predictions concerning possible ecological adaptations based on the present ecologies of extant species, without taking into account evolutionary factors such as climate adaptation and the potential disruption to gene flow caused by climate change. Similarly, conservation approaches based on population viability analysis are based on models that assume that the life histories and demographic characteristics of a species are fixed (Ashley et al. 2003). Still, as seen in the example of the Trinidad guppies, environmental factors can significantly affect life histories, with relevant consequences for the structure of a population. This can in turn produce changes in the environment, e.g. in the recycling of nutrients, creating the conditions for further evolutionary feedbacks.

Rapid contemporary evolution is the main preoccupation of evolutionary-minded conservationists, not least because anthropic drivers of rapid evolution, such as habitat loss and degradation, overharvesting, and the introduction of exotic species, are also the factors that have led to the current extinction crisis (Stockwell et al. 2003; Palkovacs et al. 2012). EEFB theory reinforces this preoccupation because it draws on the evidence that rapid contemporary evolution is a widespread phenomenon. At the same time, one of its theoretical tenets is that eco-evolutionary feedbacks can occur at any timescale, thus highlighting that just as evolutionary factors must be taken into account not only in the long, but also in the short term, ecological effects of evolutionary change might become salient over long timescales. This happens, for instance, when a newly evolved trait constructs a niche whose effects slowly accumulate over time, because it has little per capita impact or because external factors intervene to dissipate or swamp the niche. Thus, the effects of EEFB can be time-lagged (Odling-Smee et al. 2013), and this makes predictions more complex, thus more prone to error, but also more realistic.

The implementation of evolutionary-enlightened management for biodiversity conservation would imply the development of research programmes that incorporate evolution into applied ecology and resource management; the assessment of populations' short-term evolutionary potential using direct measures of genetic variation rather than the proxy of neutral molecular variation; and the use of quantitative genetics to assess the genetic variability of traits that are likely to be under selective pressure in hypothetical scenarios (Ashley et al. 2003). Ecological and evolutionary interactions are extremely complex and it is very hard to create workable predicting models. EEFB theory per se does not provide a direct answer to this problem, but offers a theoretical framework that can favour the development of such models. Post and Palkovacs' simple move of refining the NCT by splitting the EEFB into two well defined sub-processes allows to break down intricate eco-evolutionary pathways into more tractable components, which can be analysed at different spatial and temporal scales (from long-term whole-ecosystem observation to short-term, small-scale experiments). Subsequently, the general picture can be reconstructed by retracing the 
network of interactions, their strength and their variation over time (see OdlingSmee et al. 2013). As pointed out in Barker and Odling-Smee (2014), in order to be able to make predictions about the evolution of whole ecosystems and of their components, we need to bring together theories that are general and realistic enough to afford a "local theoretical unification" with precise and realistic models that describe the details of particular complex systems, providing "explanatory concrete integration" (Mitchell 2002). Theories such as EEFB are good candidates for making this synthesis, because they favour the integration of ecosystem ecology, population ecology, and evolutionary biology, and their respective methodological frameworks. If EEFB theory proved successful, then, we would be able to overcome the problem of having too simplified an account of ecosystem functioning and it would be possible to clarify the role of functional diversity within ecosystem processes.

\subsection{Conclusions}

Since the late 1990s, the development of the concept of ecosystem service for conservation policies has given new momentum to the study of the effects of biodiversity on ecosystem functioning in experimental and theoretical ecology, revitalising the traditional diversity-stability debate and fostering the development of ecosystem evolution theories.

EEFB theory emphasises the active role of organisms in shaping their environment and supports the idea that contemporary evolution is a common and widespread phenomenon. This means that species, their traits, and their ecological impacts are dynamic and vary across space and time. As a consequence, the functional contribution of biodiversity to ecosystem processes cannot be understood simply in terms of mass and energy conservation and stoichiometry rules for trophic webs, but must include, at least, the more elaborated connectance webs proposed by ecosystem engineering theory, and models of environmentally-mediated gene or phenotype associations proposed in recent developments of the NCT. Also, since contemporary evolution can be either a source of ecological change (potential disruption of ecosystem functions) or a buffer against change (preservation of ecosystem functions), in order to make predictions on the evolution of ecosystems and their capacity to sustain ecosystem services, we need to better understand ecoevolutionary interactions from the population to the whole-ecosystem level. On the whole, EEFB theory provides a non-typological image of both species and ecosystem, and challenges static visions in both ecology and evolutionary biology. On the one hand, it defies the idea that evolution is too slow to be relevant in the modelling of ecosystem processes; on the other hand, it undermines the idea that the action of organisms on their environment is too ephemeral to direct selective pressures. All in all, this calls for an evolutionary-enlightened management of biodiversity.

Ultimately, by emphasising the fact that organisms are active agents of ecological and evolutionary change rather than passive objects of selection, EEFB theory causes a shift of perspective on the role of biodiversity in the transformation of ecosystems. In fact, if "organisms and their local environments [are] integrated sys- 
tems that evolve together" (Barker and Odling-Smee 2014), then species and genetic diversity are at least as important as functional diversity for the evolution and future functioning of an ecosystem. Now, to be able to make predictions about the potential evolution of ecosystems is a fundamental feature of the ecosystem services approach. By definition, what matters the most within the ecosystem services approach is to preserve functional ecosystems, so that humans can receive benefits from them. Accordingly, biodiversity is valued for what it can deliver in terms of ecological functions (with the sole exception of cultural services, where biodiversity can be relevant for its existence value). But in a scenario of locally co-evolving organisms and ecosystems, functions can be preserved only if we can preserve the possibility of organismal change. This implies to protect species and genetic diversity together with functional diversity. While the latter grants ecosystem functioning in the present, the former influences the ability of the ecosystem to continue to function under changing conditions, which can be generated in the long as well as the short term by the internal dynamics of eco-evolutionary change or by external ecological pressures, often of anthropic origin. In ecosystem services parlance, this increases the insurance value of biodiversity. Importantly, the idea of evolving species in evolving ecosystems defies static and typological thinking in ecosystem services policies as much as in traditional biodiversity conservation, thus fostering dynamic approaches and long-term planning.

Acknowledgments This work was funded by the Fundação para a Ciência e a Tecnologia through a postdoctoral grant within the R\&D project Biodecon (PTDC/IVC-HFC/1817/2014).

\section{References}

Ashley, M. V., Willson, M. F., Pergams, O. R., O’Dowd, D. J., Gende, S. M., \& Brown, J. S. (2003). Evolutionarily enlightened management. Biological Conservation, 111(2), 115-123. https://doi.org/10.1016/S0006-3207(02)00279-3.

Barker, G., \& Odling-Smee, F. J. (2014). Integrating ecology and evolution: Niche construction and ecological engineering. In G. Barker, E. Desjardins, \& T. Pearce (Eds.), Entangled life. Organism and environment in the biological and social sciences (pp. 187-211). Dordrecht: Springer. https://doi.org/10.1007/978-94-007-7067-6.

Bassar, R. D., Marshall, M. C., López-Sepulcre, A., Zandonà, E., Auer, S. K., Travis, J., Pringle, C. M., Flecker, A. S., Thomas, S. A., Fraserg, D. F., \& Reznicka, D. N. (2010). Local adaptation in Trinidadian guppies alters ecosystem processes. Proceedings of the National Academy of Sciences, 107(8), 3616-3621. www.pnas.org/cgi/doi/10.1073/pnas.0908023107.

Boogert, N. J., Paterson, D. M., \& Laland, K. N. (2006). The implications of niche construction and ecosystem engineering for conservation biology. AIBS Bulletin, 56(7), 570-578. https:// doi.org/10.1641/0006-3568(2006)56[570:TIONCA]2.0.CO;2.

Cardinale, B. J., Duffy, J. E., Gonzalez, A., Hooper, D. U., Perrings, C., Venail, P., Narwani, A., Mace, G. M., Tilman, D., Wardle, D. A., Kinzig, A. P., Daily, G. C., Loreau, M., Grace, J. B., Larigauderie, A., Srivastava, D. S., \& Naeem, S. (2012). Biodiversity loss and its impact on humanity. Nature, 486, 59-67. https://doi.org/10.1038/nature11148. 
Costanza, R., d'Arge, R., de Groot, R., Farber, S., Grasso, M., Hannon, B., Limburg, K., Naeem, S., O’Neill, R. V., Paruelo, J., Raskin, R. G., Sutton, P., \& van den Belt, M. (1997). The value of the world's ecosystem services and natural capital. Nature, 387(6630), 253-260.

Costanza, R., de Groot, R., Braat, L., Kubiszewski, I., Fioramonti, L., Sutton, P., Farber, S., \& Grasso, M. (2017). Twenty years of ecosystem services: How far have we come and how far do we still need to go? Ecosystem Services, 28, 1-16. https://doi.org/10.1016/j.ecoser.2017.09.008.

Cottingham, K. L., Brown, B. L., \& Lennon, J. T. (2001). Biodiversity may regulate the temporal variability of ecological systems. Ecology Letters, 4(1), 72-85. https://doi. org/10.1046/j.1461-0248.2001.00189.x.

Crain, C. M., \& Bertness, M. D. (2006). Ecosystem engineering across environmental gradients: Implications for conservation and management. AIBS Bulletin, 56(3), 211-218. https://doi. org/10.1641/0006-3568(2006)056[0211:EEAEGI]2.0.CO;2.

Daily, G. C. (1997). Nature's services: Societal dependence on natural ecosystems. Washington, DC: Island Press.

Ellner, S. P., Geber, M. A., \& Hairston, N. G. (2011). Does rapid evolution matter? Measuring the rate of contemporary evolution and its impacts on ecological dynamics. Ecology Letters, 14(6), 603-614. https://doi.org/10.1111/j.1461-0248.2011.01616.x.

Fussmann, G. F., Loreau, M., \& Abrams, P. A. (2007). Eco- evolutionary dynamics of communities and ecosystems. Functional Ecology, 21, 465-477. https://doi. org/10.1111/j.1365-2435.2007.01275.x.

Ghalambor, C. K., McKay, J. K., Carroll, S. P., \& Reznick, D. N. (2007). Adaptive versus nonadaptive phenotypic plasticity and the potential for contemporary adaptation in new environments. Functional Ecology, 21(3), 394-407. https://doi.org/10.1111/j.1365-2435.2007.01283.x.

Harrison, P. A., Berry, P. M., Simpson, G., Haslett, J. R., Blicharska, M., Bucur, M., Dunford, R., Egoh, B., Garcia-Llorente, M., Geamănă, N., \& Geertsema, W. (2014). Linkages between biodiversity attributes and ecosystem services: A systematic review. Ecosystem Services, 9, 191-203. https://doi.org/10.1016/j.ecoser.2014.05.006.

Hooper, D. U., Chapin, F. S., Ewel, J. J., Hector, A., Inchausti, P., Lavorel, S., Lawton, J. H., Lodge, D. M., Loreau, M., Naeem, S., \& SchmidT, B. (2005). Effects of biodiversity on ecosystem functioning: A consensus of current knowledge. Ecological Monographs, 75(1), 3-35.

Jones, C. G., Lawton, J. H., \& Shachak, M. (1994). Organisms as ecosystem engineers. Oikos, 69, 373-386. http://www.jstor.org/stable/3545850.

Jones, C. G., Lawton, J. H., \& Shachak, M. (1997). Positive and negative effects of organisms as physical ecosystem engineers. Ecology, 78(7), 1946-1957. https://doi. org/10.1890/0012-9658(1997)078[1946:PANEOO]2.0.CO;2.

Jones, L. E., et al. (2009). Rapid contemporary evolution and clonal food web dynamics. Philosophical Transactions of the Royal Society B, 364, 1579-1591. https://doi.org/10.1098/ rstb.2009.0004.

Justus, J., Colyvan, M., Regan, H., \& Maguire, L. (2009). Buying into conservation: Intrinsic versus instrumental value. Trends in Ecology and Evolution, 24(4), 187-191. https://doi. org/10.1016/j.tree.2008.11.011.

Kinnison, M. T., \& Hairston, N. G. (2007). Eco-evolutionary conservation biology: Contemporary evolution and the dynamics of persistence. Functional Ecology, 21(3), 444-454. https://doi. org/10.1111/j.1365-2435.2007.01278.x.

Kokko, H., \& Lopez-Sepulcre, A. (2007). The ecogenetic link between demography and evolution: Can we bridge the gap between theory and data? Ecology Letters, 10, 773-782. https://doi. org/10.1111/j.1461-0248.2007.01086.x.

Laland, K. N., Odling-Smee, F. J., \& Feldman, M. W. (1999). Evolutionary consequences of niche construction and their implications for ecology. Proceedings of the National Academy of Sciences, 96(18), 10242-10,247. https://doi.org/10.1073/pnas.96.18.10242.

Laland, K. N., \& Sterelny, K. (2006). Perspective: Seven reasons (not) to neglect niche construction. Evolution, 60(9), 1751-1762. https://doi.org/10.1111/j.0014-3820.2006.tb00520.x.

Lill, J. T., \& Marquis, R. J. (2003). Ecosystem engineering by caterpillars increases insect herbivore diversity on white oak. Ecology, 84(3), 682-690. https://www.jstor.org/stable/3107862. 
Loreau, M. (2010). Linking biodiversity and ecosystems: Towards a unifying ecological theory. Philosophical Transactions of the Royal Society, B: Biological Sciences, 365, 49-60. https:// doi.org/10.1098/rstb.2009.0155.

Loreau, M. (2010a). The challenges of biodiversity science. Oldendorf/Luhe: International Ecology Institute.

Loreau, M. (2010b). From populations to ecosystems: Theoretical foundations for a new ecological synthesis (MPB-46). Princeton/Woodstock: Princeton University Press.

MA, Millennium Ecosystem Assessment. (2003). Ecosystems and human well-being: A framework for assessment. Washington, DC: Island Press.

MA, Millennium Ecosystem Assessment. (2005). Ecosystems and human well-being: Synthesis. Washington, DC: Island Press.

Maclaurin, J., \& Sterelny, K. (2008). What is biodiversity? Chicago: University of Chicago Press.

May, R. M. (1973). Stability and complexity in model ecosystems. Monographs in population biology. Princeton: Princeton University Press.

MacArthur, R. H. (1955). Fluctuations of animal populations and a measure of community stability. Ecology, 36, 533-535. https://doi.org/10.2307/1929601.

Mace, G. M., \& Purvis, A. (2008). Evolutionary biology and practical conservation: Bridging a widening gap. Molecular Ecology, 17, 9-19. https://doi.org/10.1111/j.1365-294X.2007.03455.x.

Mace, G. M., Norris, K., \& Fitter, A. H. (2012). Biodiversity and ecosystem services: A multilayered relationship. Trends in Ecology \& Evolution, 27(1), 19-26. https://doi.org/10.1016/j. tree.2011.08.006.

Maquire, L. A., \& Justus, J. (2008). Why intrinsic value is a poor basis for conservation decisions. BioScience, 58, 910-911.

Menge, B. A., Berlow, E. L., Blanchette, C. A., Navarrete, S. A., \& Yamada, S. B. (1994). The keystone species concept: Variation in interaction strength in a rocky intertidal habitat. Ecology Monographs, 64, 249-286. https://doi.org/10.2307/2937163.

McCauley, D. J. (2006). Selling out on nature. Nature, 443, 27-28.

Mitchell, S. D. (2002). Integrative pluralism. Biology and Philosophy, 17(1), 55-70.

Naeem, S. (2002). Ecosystem consequences of biodiversity loss: The evolution of a paradigm. Ecology, 83, 1537-1552. https://doi.org/10.1890/0012-9658(2002)083[1537:ECOBLT]2.0 . $\mathrm{CO} ; 2$.

Naess, A. (1973). The shallow and the deep, long range ecology movement. A summary. Inquiry, $16,95-100$.

Norton, B. G. (1986). The preservation of species: The value of biological diversity. Princeton: Princeton University Press.

Odling-Smee, F. J., Laland, K. N., \& Feldman, M. W. (2003). Niche construction: The neglected process in evolution. In Monographs in population biology. Princeton: Princeton University Press.

Odling-Smee, J. F., Erwin, D. H., Palkovacs, E. P., Feldman, M. W., \& Laland, K. N. (2013). Niche construction theory: A practical guide for ecologists. The Quarterly Review of Biology, 88(1), $3-28$.

Paine, R. T. (1966). Food web complexity and species diversity. Am. Nat. 100, 65-75. https://doi. org/10.1086/282400.

Palkovacs, E. P., Kinnison, M. T., Correa, C., Dalton, C. M., \& Hendry, A. P. (2012). Fates beyond traits: Ecological consequences of human-induced trait change. Evolutionary Applications, 5(2), 183-191. https://doi.org/10.1111/j.1752-4571.2011.00212.x.

Pimm, S. L. (1984). The complexity and stability of ecosystems. Nature, 307, 321-326. https:// doi.org/10.1038/307321a0.

Post, D. M., \& Palkovacs, E. P. (2009). Eco-evolutionary feedbacks in community and ecosystem ecology: Interactions between the ecological theatre and the evolutionary play. Philosophical Transactions of the Royal Society B, 364, 1629-1640. https://doi.org/10.1098/rstb.2009.0012.

Redford, K. H., \& Adams, W. M. (2009). Payment for ecosystem services and the challenge of saving nature. Conservation Biology, 23, 785-787. https://doi.org/10.1111/j.1523-1739.2009.01271.x. 
Reyers, B., Polasky, S., Tallis, H., Mooney, H. A., \& Larigauderie, A. (2012). Finding common ground for biodiversity and ecosystem services. BioScience, 62(5), 503-507. https://doi. org/10.1525/bio.2012.62.5.12.

Santamaría, L., \& Mendez, P. F. (2012). Evolution in biodiversity policy-current gaps and future needs. Evolutionary Applications, 5(2), 202-218. https://doi. org/10.1111/j.1752-4571.2011.00229.x.

Sarkar, S. (2005). Biodiversity and environmental philosophy: An introduction. New York: Cambridge University Press.

Singer, P. (1975). Animal liberation: A new ethics for our treatment of animals. New York: Random House.

Srivastava, D. S., \& Vellend, M. (2005). Biodiversity-ecosystem function research: Is it relevant to conservation? Annual Review of Ecology, Evolution, and Systematics, 36, 267-294. https://doi. org/10.1146/annurev.ecolsys.36.102003.152636.

Stockwell, C. A., Hendry, A. P., \& Kinnison, M. T. (2003). Contemporary evolution meets conservation biology. Trends in Ecology \& Evolution, 18, 94-101. https://doi.org/10.1016/ S0169-5347(02)00044-7.

TEEB. (2010). The economics of ecosystems and biodiversity: Ecological and economic foundations. Ed. P. Kumar. London/Washington, DC: Earthscan.

Thompson, S. C. G., \& Barton, M. A. (1994). Ecocentric and anthropocentric attitudes toward the environment. Journal of Environmental Psychology, 14(2), 149-157. https://doi.org/10.1016/ S0272-4944(05)80168-9.

Thompson, J. N. (1998). Rapid evolution as an ecological process. Trends in Ecology \& Evolution, 13(8), 329-332. https://doi.org/10.1016/S0169-5347(98)01378-0.

Westman, W. E. (1977). How much are nature's services worth? Science, 197(4307), 960-964.

Whitham, T. G., Bailey, J. K., Schweitzer, J. A., Shuster, S. M., Bangert, R. K., LeRoy, C. J., Lonsdorf, E. V., Allan, G. J., DiFazio, S. P., Potts, B. M., \& Fischer, D. G. (2006). A framework for community and ecosystem genetics: From genes to ecosystems. Nature Reviews Genetics, 7, 510-523. https://doi.org/10.1038/nrg1877.

Williams, H. T. P., \& Lenton, T. M. (2007). Artificial selection of simulated microbial ecosystems. Proceedings of the National Academy of Sciences, 104, 8918-8923. https://doi.org/10.1073/ pnas.0610038104.

Wright, J. P., \& Jones, C. J. (2006). The concept of organisms as ecosystem engineers ten years on: Progress, limitations, and challenges. BioScience, 56(3), 203-209. https://doi. org/10.1641/0006-3568(2006)056[0203:TCOOAE]2.0.CO;2.

Open Access This chapter is licensed under the terms of the Creative Commons Attribution 4.0 International License (http://creativecommons.org/licenses/by/4.0/), which permits use, sharing, adaptation, distribution and reproduction in any medium or format, as long as you give appropriate credit to the original author(s) and the source, provide a link to the Creative Commons licence and indicate if changes were made.

The images or other third party material in this chapter are included in the chapter's Creative Commons licence, unless indicated otherwise in a credit line to the material. If material is not included in the chapter's Creative Commons licence and your intended use is not permitted by statutory regulation or exceeds the permitted use, you will need to obtain permission directly from the copyright holder.

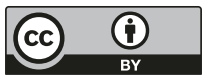

